\title{
Clinical-epidemiological profile of deaths from influenza with history of timely vaccination, Mexico 2010-2018
}

\author{
Pablo Antonio Kuri-Morales, ${ }^{1}$ Guadalupe Díaz del Castillo-Flores, ${ }^{2 *}$ Andrés Castañeda-Prado ${ }^{1}$, and \\ Salma Rosario Pacheco-Montes ${ }^{3}$ \\ ${ }^{1}$ Universidad Nacional Autónoma de México, Faculty of Medicine, Ciudad de México; ${ }^{2}$ Servicios de Salud de Veracruz, Sub-directorate of Prevention
} and Control of Diseases, Veracruz; ${ }^{3}$ Secretaría de Salud, General Directorate of Epidemiology, Mexico City. Mexico

\begin{abstract}
Introduction: Influenza epidemics are of higher risk at the extremes of life and in people with comorbidities. Effective vaccination prevents the occurrence of serious cases and decreases mortality. Objective: To describe deaths from influeenza with a history of timely vaccination, from the 2010 to the 2018 season in Mexico. Method: Cross-sectional, descriptive study where the Influenza Epidemiological Surveillance System database was used. Results: From 2010 to 2018, 65 vaccinated individuals died from influenza, from which $55 \%$ of cases $(n=36)$ were due to type $A(H 1 N 1), 51 \%(n=33)$ were females, median age was 57 years, $21 \%(n=14)$ did not meet the operational definition of influenza-like illness or severe acute respiratory infection, $83 \%(n=54)$ had at least one comorbidity, with the most common being diabetes mellitus and hypertension (32\% each); $55 \%(n=36)$ of deaths received antiviral treatment and only $8 \%(n=5)$ had no comorbidities and received treatment with oseltamivir. Conclusions: Deaths from influenza with timely vaccination represent a very low percentage of the
\end{abstract} totality. Vaccination against influenza has been a specific prevention strategy that decreases disease burden.

KEY WORDS: Human influenza. Cause of death. Vaccination.

\section{Introduction}

Influenza, seasonal or pandemic, is a disease caused by an RNA virus that belongs to the Orthomyxoviridae family. There are three types of influenza viruses: $A, B$ and $C$, which in turn include different subtypes. Transmission of the virus is by air or through fomites, and has high pandemic potential. ${ }^{1,2}$

Influenza A viruses are divided into subtypes according to the characterization of two surface antigens: hemagglutinin and neuroaminidase. Influenza A (H1N1 and H3N2) and B viruses circulate simultaneously in the world. The new variants of influenza virus appear as a result of point mutations and recombination events that occur during viral replication, generating frequent antigenic variations. ${ }^{2}$
Influenza A virus new or very different subtypes resulting from antigenic variations have the potential to cause a pandemic, since they are able to cause disease in humans and to maintain effective, sustained transmission, especially when there is little or no previous immunity in the population. ${ }^{2}$

Influenza epidemics can seriously affect the population and are riskier in the extremes of life and in people with comorbidities. Throughout history, influenza has caused major epidemics that have translated into high mortality rates. Epidemiological influenza surveillance and vaccination are essential for the prevention of outbreaks and epidemics that can endanger poptilation's life. Effective vaccination prevents the occurrence of serious cases and decreases mortality. 1,3

Efficacy and effectiveness of the influenza vaccine depend on numerous factors such as age,

\section{Correspondence:}

*Guadalupe Díaz del Castillo-Flores

E-mail: guadelupediazdelcastilloflores@gmail.com
Date of reception: 26-09-2018

Date of acceptance: 21-02-2019

DOI: 10.24875/GMM.M20000327
Gac Med Mex. 2019;155:423-429

Contents available at PubMed

www.gacetamedicademexico.com 0016-3813/@ 2019 Academia Nacional de Medicina de México, A.C.. Published by Permanyer. This is an open access article under the CC BY-NC-ND license (http://creativecommons.org/licenses/by-nc-nd/4.0/). 
immunocompetence, degree of similarity between the viruses contained in the vaccine and circulating viruses, among others (Table 1). ${ }^{4}$

After vaccination, the levels of viral proteins hemagglutinin and neuroaminidase slowly decrease; the reduction could be higher than $50 \%$ after 600 days. ${ }^{3,5}$ In adults older than 60 years, seroprotection after vaccination against type $A$ influenza has been reported; it has been longer than four months for the H3N2 and H1N1 components. ${ }^{6}$ One study in Spain concluded that people with a history of vaccination more than 200 days prior are at higher risk of contracting the disease than those who were vaccinated in recent days. ${ }^{7}$ In the United Kingdom, the range of effectiveness in the 2011-2012 season for influenza A (H3N2) was calculated at $53 \%$ in people vaccinated less than three months prior and in $12 \%$ in people vaccinated three or more months prior. ${ }^{8}$

The treatment for influenza consists of neuraminidase inhibitors: oseltamivir and zanamivir. Clinical trials and observational data show that early antiviral treatment can shorten the duration of fever and disease symptoms and reduce the risk of complications. ${ }^{9}$

In Mexico, influenza epidemiological surveillance is conventional and sentinel, according to the standards recommended by the World Health Organization. The special surveillance system is called SISVEFLU (Sistema de Vigilancia Epidemiológica de Influenza - Influenza Epidemiological Surveillance System) and is part of the National Epidemiological Surveillance System. SISVEFLU has 559 primary, secondary and tertiary care influenza monitoring health units (USMI - Unidades de Salud Monitoras de Influenza) belonging to the National Health System in Mexico, distributed in all 32 states of the country. SISVEFLU main goal is to monitor the type of etiologic agent that circulates and produces severe acute respiratory infection (SARI) in Mexico and to identify new cases of respiratory disease associated with the presence of new agents or any increase in seasonal influenza. ${ }^{10}$

Influenza epidemiological surveillance includes the following definitions:

- Influenza-like illness (ILI): subjects of any age who present with or refer having had fever higher than or equal to $38^{\circ} \mathrm{C}$, cough and headache accompanied by one or more of the following signs or symptoms: rhinorrhea, coryza, arthralgia, myalgia, prostration, odynophagia, chest pain, abdominal pain, nasal congestion or diarrhea.

- SARl: subjects of any age who have difficulty breathing, with a history of fever higher than or

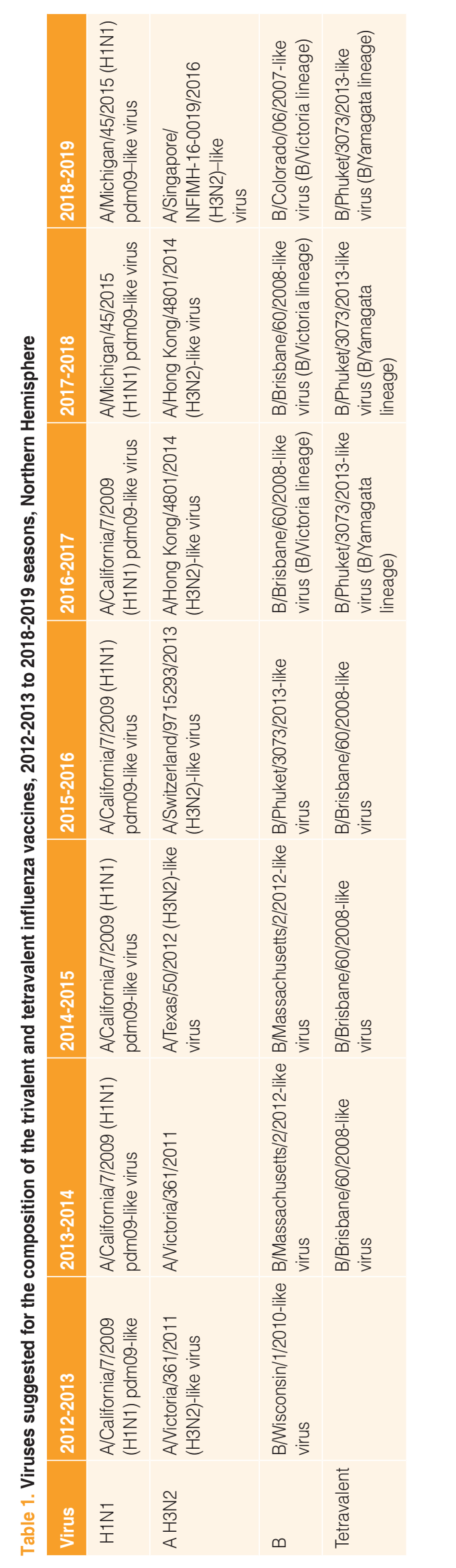




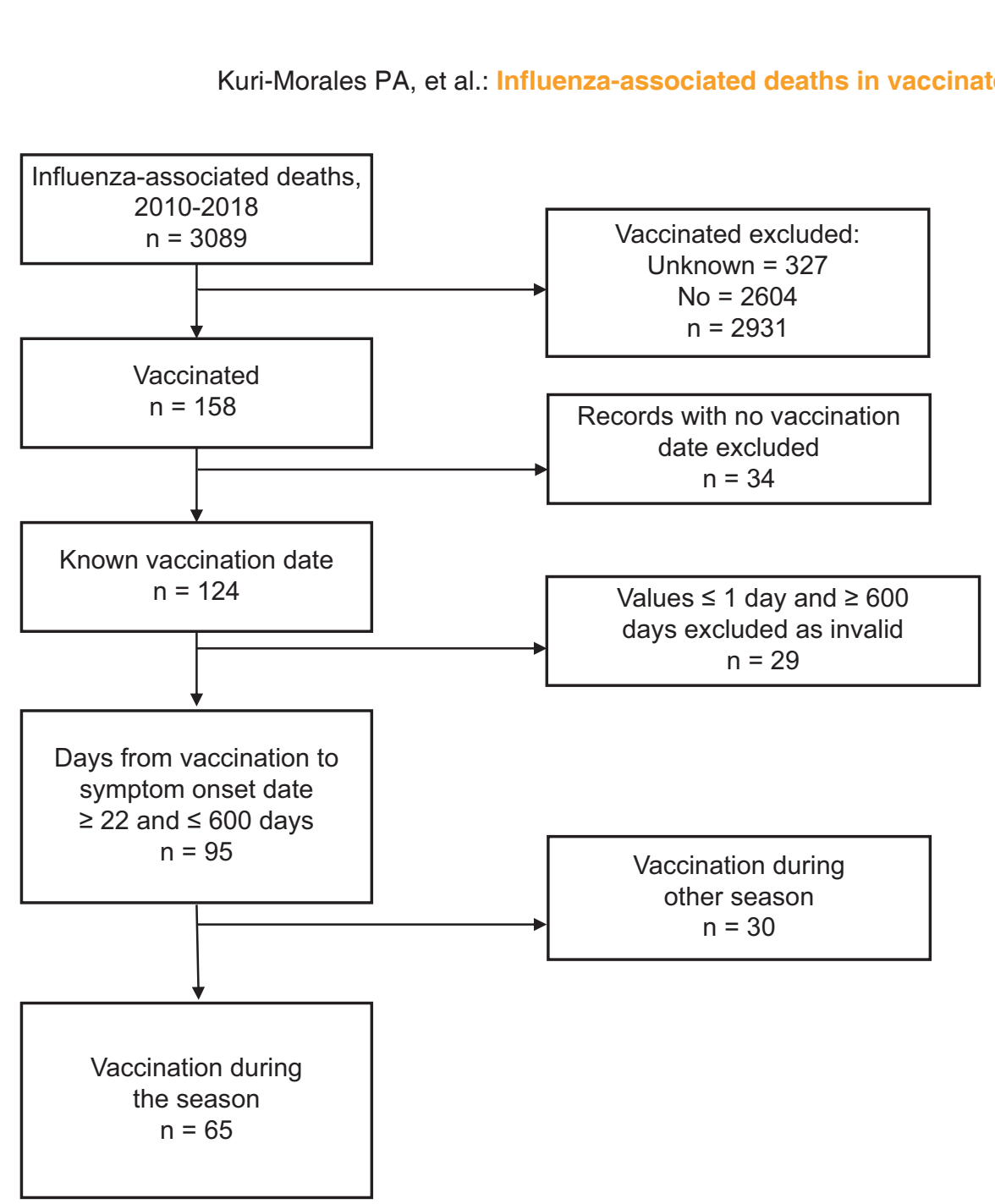

Figure 1. Flow chart of the selection process of deaths with a history of timely influenza vaccination.

equal to $38^{\circ} \mathrm{C}$ and cough, or one or more of the following symptoms: general deterioration, chest pain or polypnea.

- Influenza-associated death: deceased patient who has met the operational definition of ILI/ SARI and who has a positive result for influenza issued by one of the laboratories endorsed by the National Network of Public Health Laboratories, and whose death certificate contains as a basic cause the diagnosis of influenza or pneumonia. An influenza-associated death is subject to epidemiological surveillance, and thus it must be necessarily ratified or rectified by the Epidemiological and Statistical Mortality System methodology. ${ }^{11}$

The purpose of this study is to characterize influenza-associated deaths with a history of vaccination ratified by the Epidemiological and Statistical Mortality System from the $2010-2011$ to the 2017-2018 season in Mexico.

\section{Method}

Descriptive cross-sectional study where the SISVEFLU database for the years 2010-2018 was used. The included variables are part of the influenza case sțity: age, gender, pregnancy, state of residence, occupation, date of admission to the healthcare unit, date of onset of symptoms, comorbidity, probable diagnesis, treatment with antiviral drugs, type of antiviral drug, history of influenza vaccine, date of vaccination against influenza, if vaccination history is unknown, sample taking, sample result and date of death.

Initially, all influenza-associated deaths from 2010 to 2018 were included; subsequently, those without a vaccination history, with an unknown history thereof or without a record of the date of influenza vaccination were excluded. In addition, records with a vaccination date of less than or equal to one day (no seriousty ill patient was vaccinated during his/her care) or otder than 600 days (after this period, antibodies are reduced below $50 \%$ ) were excluded. 


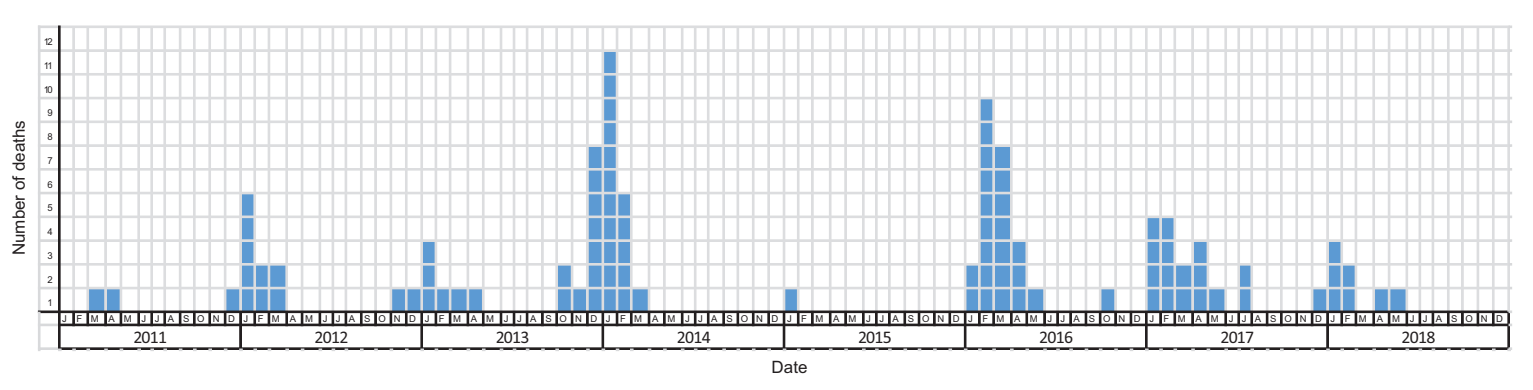

Figure 2. Evolution in time of influenza-associated deaths with a history of vaccination, Mexico 2010-2018 ( $n=65)$.

Deaths with a vaccination history corresponding to the season of each one of the analyzed years dated at least 21 days prior (average time for vaccination-induced immune response) were selected and those whose vaccination date corresponded to another season were excluded (Fig. 1).

\section{Results}

From epidemiological week 40 of 2010 to week 20 of 2018 there were 3089 influenza-associated deaths, out of which only 65 (2.1\% of total deaths) were reported with a vaccination history with the seasonal vaccine and with at least 21 days from vaccination to the onset of influenza symptoms (Fig. 1). The highest number of deaths was recorded in January $2014(17 \%, n=11)$ (Fig. 2). Average number of days from vaccination to the onset of symptoms was 78; 88 $\%(n=57)$ of deaths had a death date record. The average number of days from the onset of symptoms to the date of death was 10.3 (median: 9; range: 0-37).

Most deaths $(n=36)$ were caused by subtype $A$ (H1N1); 15 by $A(H 3)$, eight by influenza $B$ and two were not subtyped (Fig. 3).

\section{Socio-demographic characterization}

All deaths $(n=65)$ were reported by influenza monitoring healthcare units. According to the place of occurrence, $17 \%$ of deaths $(n=11)$ corresponded to Mexico City, $12 \%(n=8)$ to the State of Mexico, $12 \%$ $(\mathrm{n}=8)$ to Jalisco, $9 \%(\mathrm{n}=6)$ to Michoacán and $6 \%$ $(n=4)$ to Veracruz. Gender distribution was very similar: $51 \%(n=33)$ were females. Median age was 57 years with a range of 1 to 94 . The most common occupation was homemaking ( $32 \%, \mathrm{n}=21)$.

\section{Operational definition: ILI/SARI}

Among all 65 deaths, $21 \%(n=14)$ did not meet the operational definition of ILI or SARI despite having

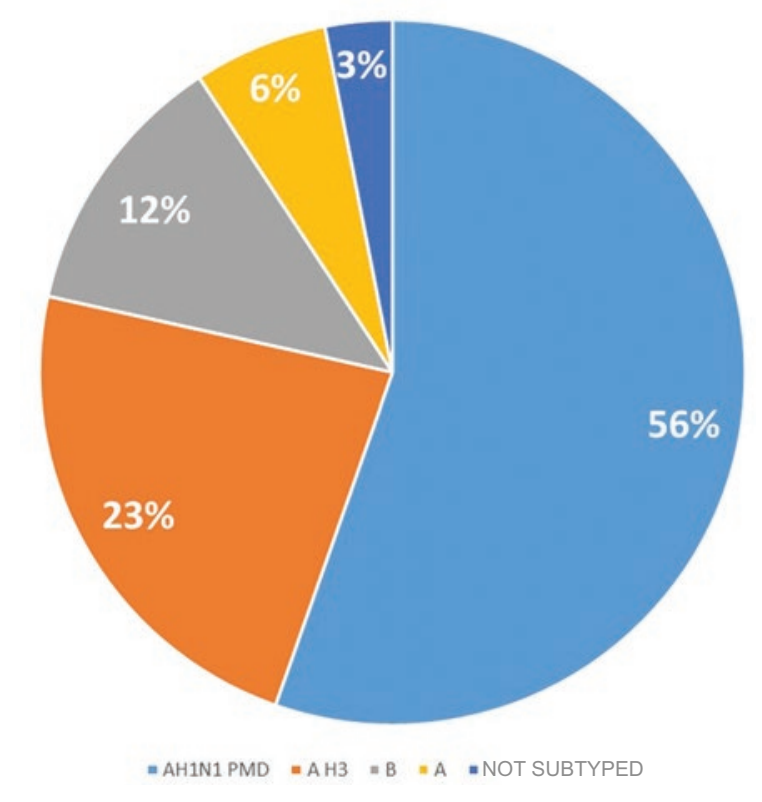

Figure 3. Distribution of influenza-associated deaths with a history of vaccination by subtype, Mexico 2010-2018 $(n=65)$.

an influenza-positive final result. The five deaths in children younger five years met the operational definition in a $100 \%$. Of the 32 deaths in the six to 64 year age group, seven (22\%) did not meet cthe operational definition of ILI or SARI, and of the 28 deaths in subjects older than 65 years, seven (25\%) didn't either. We consider that patient-inherent conditions determined that 14 deaths did not strictly meet the operational definition; however, when there was suspicion by the clinician, samples were taken, which were positive.

\section{Comorbidities}

In $83 \%$ of deaths $(n=54)$ there was at least one comorbidity, in $29 \%(n=19)$ one, in $26 \%(n) 17)$ two, in $18 \%(n=12)$ three, in $8 \%(n=5)$ four and in $1.5 \%(n=1)$ five. Among those younger than five years, only one had one comorbidity, recorded as "other" (Table 2). 
Table 2. Frequency of comorbidities in the cases of influenza-associated death with a history of vaccination, Mexico 2010-2018 $(n=54)$

\begin{tabular}{|l|c|c|}
\hline Comorbidity & n & $\%$ \\
\hline Diabetes mellitus & 21 & 32 \\
\hline Hypertension & 21 & 32 \\
\hline Morbid obesity & 15 & 23 \\
\hline Chronic kidney failure & 12 & 18 \\
\hline Smoking & 11 & 17 \\
\hline Immunosuppression & 10 & 15 \\
\hline COPD & 7 & 11 \\
\hline Cardiac disease & 7 & 11 \\
\hline Other comorbidity & 7 & 11 \\
\hline Asthma & 2 & 3 \\
\hline HIV/AIDS & 1 & 2 \\
\hline $\begin{array}{l}\text { COPD = chronic obstructive pulmonary disease, HIV/AIDS }=\text { human immunodeficiency } \\
\text { virus/acquired immunodeficiency syndrome. }\end{array}$ &
\end{tabular}

\section{Antiviral treatment}

Only $55 \%$ of deceased cases $(n=36)$ received antiviral treatment, 35 with oseltamivir and one with zanamivir. Of these, only five had the treatment initiation date recorded; $6 \%$ of the deceased $(n=4)$ had recorded having started treatment within the first 72 hours after symptom onset; in one case, antiviral initiation was recorded on day 13 after the onset of symptoms and death was recorded on day 17.

Table 3 describes the cases of deceased subjects with a history of vaccination, without comorbidities and with treatment with oseltamivir, although the treatment initiation date was unknown in all of them.

\section{Discussion}

Given that SISVEFLU captures $100 \%$ of severe acute respiratory infection cases, all 3089 deaths reported are considered the universe of influenza-associated deaths, even when one third of infections are asymptomatic and the cases have to meet criteria that are subject to surveillance, as the operational definition. The fact that only 65 deaths ( $2.1 \%$ of total) had a history of vaccination with the vaccine suggested for the season and a period of at least 21 days from vaccination to the onset of symptoms, suggests that immunization against seasonal influenza is a profitable strategy, especially when herd immunity is considered, as well as that a reduction in the burden of disease and, therefore, in health care costs and sociodemographic costs has been demonstrated. ${ }^{12}$

The probability for the vaccine to be cost-effective to prevent death has been described to be of $100 \%$, and to avoid complications, $96.7 \% .^{12}$

The frequency of influenza-associated deaths with a history of vaccination was consistent with the occurrence of cases in the seasons; the 2013-2014 season was the one with the highest number of recorded deaths. ${ }^{13}$ This suggests that influenza-associated deaths could have been caused by complications $\bar{a}$ and situations that worsened the cases; individualizing the investigation of each death would be the subject of another study.

ILI or SARI operational definition is used for epidemiological surveillance purposes and has been shōwn to be sensitive. In clinical practice, the physician should start antiviral treatment within the first 48 hours in patients with cough and fever when influenza vifuses are known to be circulating in the community ${ }^{14}$ i.e., the fact that a case does not meet the operational definition is not a reason to delay antiviral treatment.

As previously described in the literature and reported by the National Epidemiological Surveillance System, most influenza-associated deaths have at least one comorbidity that worsens the natural history of the disease. In this study, $83 \%$ of cases had at least one comorbidity, such as overweight, obesity, diabetes or congestive heart failure, which may have triggered a low response of the host's immune system. Since the 2009 pandemic, obesity was recognized as a risk factor for influenza complications; this is important, since, in Mexico, $30 \%$ of children, $40 \%$ of àdolescents and $70 \%$ of adults are overweight or obese . $^{15}$ thus, we are facing new challenges in disease prevention, since obese adults with a history of vaccination have up to twice the risk of developing influenza due to poor T-cell function. ${ }^{16}$

The occurrence of only 10 deaths among patients with immunosuppression in a universe of 3089 deatths also suggests an achievement in the country regarding the management of patients living with human immunodeficiency virus infection and an adequiate compliance with vaccination recommendations in individuals with immunosuppression. ${ }^{17}$

People living with diabetes are more susceptible to contracting influenza infection; cardiovascular disèases associated with influenza have also been reported to be able to lead to significant hemodynamic compromise that requires cardiac support. ${ }^{18}$ 
Table 3. Description of influenza-associated deaths with a history of vaccination, without comorbidities and with antiviral treatment

\begin{tabular}{|c|c|c|c|c|c|c|c|c|}
\hline Case & $\begin{array}{l}\text { Age } \\
\text { gender }\end{array}$ & Occupation & Sudden onset & $\begin{array}{l}\text { Meets operational } \\
\text { definition }\end{array}$ & $\begin{array}{l}\text { Vaccination to symptom } \\
\text { onset (days) }\end{array}$ & $\begin{array}{l}\text { Symptom onset } \\
\text { to death (days) }\end{array}$ & Subtype & $\stackrel{1}{\frac{1}{\lambda}}$ \\
\hline 1 & $\begin{array}{l}1 \\
\text { Female }\end{array}$ & - & No & ILI & 57 & 18 & A H1N1 & \\
\hline 2 & $\begin{array}{l}2 \\
\text { Male }\end{array}$ & - & Yes & ILI and SARI & 93 & 3 & $\mathrm{AH} 3$ & (2) \\
\hline 3 & $\begin{array}{l}38 \\
\text { Female }\end{array}$ & Homemaker & No & ILI & 50 & - & A H1N1 & PMD \\
\hline 4 & $\begin{array}{l}46 \\
\text { Female }\end{array}$ & Homemaker & No & SARI & 66 & 23 & A H1N1 & $\begin{array}{l}\text { PMD } \\
\text { 으 }\end{array}$ \\
\hline 5 & $\begin{array}{l}82 \\
\text { Female }\end{array}$ & Homemaker & Yes & ILI and SARI & 51 & 10 & $\mathrm{AH} 3$ & $\begin{array}{l}\frac{5}{+} \\
\frac{4}{0}\end{array}$ \\
\hline 6 & $\begin{array}{l}86 \\
\text { Female }\end{array}$ & Homemaker & Yes & ILI and SARI & 44 & 4 & $\mathrm{AH} 3$ & $\frac{c}{0}$ \\
\hline ILI = infl & e illnes & $\mathrm{RI}=$ severe acu & iratory infection. & & & & & $\begin{array}{l}\text { 늘 } \\
\text { อ }\end{array}$ \\
\hline
\end{tabular}

It is important for public health to specify the other comorbidities that occurred in these deaths and that the system does not allow clarification of to define new risk groups and vaccination strategies.

There is solid and consistent evidence that vaccination during pregnancy protects women and their newborns against influenza infection. ${ }^{19}$ The fact of not having found any deaths in the country involving pregnant women with a history of vaccination for the season indicates an excellent adherence to the goal of vaccination at any trimester of pregnancy. ${ }^{17}$

Of the six influenza-associated deceased cases with a history of vaccination, without comorbidities and who received antiviral treatment, four corresponded to individuals at extremes of life, which is consistent with the knowledge that the immune system may be immature in children or declining in older adults. ${ }^{20}$

\section{Conclusions}

According to our results, influenza-associated deaths in patients with a history of vaccination represent a very low percentage of total deaths, only $2.1 \%$.

The existence of comorbidities and belonging to the age groups at the extremes of life contribute to influenza-associated mortality.

Since its implementation, influenza vaccination has been a specific prevention strategy that has reduced the burden of disease in the general healthy population and mortality in specific populations. This component of the Universal Vaccination Program is crucial to protect the Mexican population from one of the most important communicable diseases of our era.
The reduction in influenza-associated mortality is the result of the reach of health promotion, the strength of the Epidemiological Surveillance System, the gerarantee in the supply of treatment and, most importantly, of the consistency of the vaccination program.

\section{Acknowledgements}

To the General Directorate of Epidemiology, doctors Cuitláhuac Ruiz Matus, María Eugenia Jiménez Cơrona and José Alberto Díaz Quiñonez, who are responsible for the SISVEFLU operation at the federal, state and local level, for the information, and to the personnel of the National Network of State Public Health Laboratories.

\section{Declaration of conflicts of interest and funding}

The authors declare that they have conflicts of interest. There wasn't any type of financing involved with the conduction of this work either.

\section{References}

1. Fact Sheet: Flu [en línea]. Suiza: Organización Mundial de 2018.

2. Hutchinson EC. Influenza virus. Trends Microbiol. 2018;26:809-810

3. Antecedentes del ACIP 2017-2018 [en línea]. EE. UU.: Centers for Disease Control and Prevention; 2018.

4. Nichol KL. Heterogeneity of influenza case definitions and implications for interpreting and comparing study results. Vaccine. 2006;10:6726-6728.

5. Petrie JG, Ohmit SE, Johnson E, Truscon R, Monto AS. Persistehce of antibodies to influenza hemagglutinin and neuraminidase following one or two years of influenza vaccination. J Infect Dis. 2015;212:1914-1922.

6. Skowronski DM, Tweed SA, De Serres G. Rapid decline of influenza vaccine-induced antibody in the elderly: is it real, or is it relevant? J Infect Dis. 2008;197(4):490-502. 
7. Castilla J, Martínez-Baz I, Martínez-Artola V, Reina G, Pozo F, García-Cenoz $M$, et al. Decline in influenza vaccine effectiveness with time after vaccination, Navarre, Spain, season 2011/12. Euro Surveill. 2013;18:20388.

8. Pebody R, Andrews N, McMenamin J, Durnall H, Ellis J, Thompson Cl et al. Vaccine effectiveness of 2011/12 trivalent seasonal influenza vaccine in preventing laboratory-confirmed influenza in primary care in the United Kingdom: evidence of waning intra-seasonal protection. Euro Surveill. 2013;18:20389.

9. Fiore AE, Fry A, Shay D, Gubareva L, Bresee JS, Uyeki TM, et al. Antiviral agents for the treatment and chemoprophylaxis of influenza: recommendations of the Advisory Committee on Immunization Practices (ACIP). MMWR Recomm Rep. 2011;60:1-24.

10. Manual para la vigilancia epidemiológica de influenza. México: Secretaría de Salud/Dirección General de Epidemiología; 2014

11. Manual de procedimientos estandarizados para el sistema estadístico epidemiológico de las defunciones (SEED). México: Secretaría de Salud/ Dirección General de Epidemiología; 2012.

12. Yang KC, Hung HF, Chen MK, Chen SL, Fann JC, Chiu SY, et al. Cost-effectiveness analysis of universal influenza vaccination: application of the susceptible-infectious-complication-recovery model. Int J Infect Dis. 2018;73:102-108

13. Ruiz-Matus C, Kuri-Morales $P$, Narro-Robles J. Behavior of influenza seasons in Mexico from 2010 to 2016: analysis and prospective. Gac Med Mex. 2017;153:205-213.
14. Yang JH, Huang PY, Shie SS, Yang S, Tsao KC, Wu TL, et al. Predictive symptoms and signs of laboratory-confirmed influenza: a prospective surveillance study of two metropolitan areas in Taiwan. Medicine (Baltimore). 2015;94:e1952.

15. Encuesta Nacional de Salud y Nutrición de Medio Camino 2016. Informe final de resultados. México: Instituto Nacional de Salud Pública; 2016.

16. Neidich SD, Green WD, Rebeles J, Karlsson EA, Schultz-Cheffy S, Noah TL, et al. Increased risk of influenza among vaccinated adults, who are obese. Int J Obes (Lond). 2017;41:1324-1330.

17. Lineamientos Generales del Programa de Vacunación Universal y Semanas Nacionales de Salud 2018. [en línea]. México: Secretaría de Salud/ Centro Nacional para la Salud de la Infancia y Adolescencia; 2018.:

18. Sellers SA, Hagan RS, Hayden FG, Fischer WA. The hidden burden of influenza: A review of the extralpulmonary complications of inflyenza infection. Influenza Other Respir Viruses. 2017;11:372-393.

19. Mazagatos C, Delgado-Sanz C, Oliva J, Gherasim A, Larrauri A, Spanish Influenza Surveillance System. Exploring the risk of severe outcomes and the role of seasonal influenza vaccination in pregnant women hospitalized with confirmed influenza, Spain, 2010/11-2015/16. PLOSONE. 2018;13:e0200934.

20. Memoli MJ, Athota R, Reed S, Czajkowski L, Bristol T, Proudfoot Kcet al. The natural history of influenza infection in the severely immunocompromised vs nonimmunocompromised hosts. Clin Infect Dis. 2014;58:214224. 